\title{
Análise da Tecnologia Fotovoltaica de CdTe para uma Central Geradora de 1MWp no Semiárido Brasileiro
}

\author{
Analysis of Photovoltaic Technology of CdTe to a Generating Central of $1 \mathrm{MWp}$ in the \\ Brazilian Semi-arid
}

\section{Eduardo Filipe Araújo Galindo ${ }^{1}$ https://orcid.org/0000-0002-7679-6127}

\author{
José Bione de Melo Filho ${ }^{1}$ (Bhttps://orcid.org/0000-0002-9283-3362
}

${ }^{1}$ Escola Politécnica de Pernambuco, Universidade de Pernambuco, Recife, Brasil.

E-mail do autor principal: Eduardo Galindo eduardofag20@gmail.com

\section{RESUMO}

A procura por uma geração de energia mais eficiente e adequada para o semiárido brasileiro foi o objetivo desse estudo no qual foi analisado o uso dos painéis fotovoltaicos de CdTe para uma central geradora de $1 \mathrm{MWp}$ no semiárido Brasileiro, especificamente na cidade de Petrolina. Com isso foram feitas simulações de geração de energia elétrica usando um software específico eposterirormente foram feitas análises e comparações do uso da tecnologia de CdTe em relação aos outros principais tipos de painéis solares no mercado global atual. Verificou-seque os painéis de telureto de cádmio obtiveram o Performance Ratiode $84,86 \%$ que foi o maior PR dentro painéis os analisados e mostrou-se também ser o mais ideal quando o fator é ter a menor perdade energia fotovoltaica decorrente a temperatura que foi de $-9 \%$ e o ganho pela qualidade do modulo fotovoltaico que foi de $+1.3 \%$. Com isso o sistema fotovoltaico de CdTe foi o que mais gerou energia durante o ano, com um total de $1667 \mathrm{MWh}$ e que consequentemente foi o que teve a maior viabilidade energética.

PALAVRAS-CHAVE: Energia Fotovoltaica; Semiárido Brasileiro; CdTe;

\begin{abstract}
The search for a more efficient and adequate energy generation for the Brazilian semi-arid was the objective of this study in which the use of panels CdTe photovoltaic panels for a $1 \mathrm{MWp}$ generating plant in the Brazilian semiarid, specifically in the city of Petrolina. With this, simulations of electric power generation were maid using specific software and that subsequent analyzes and comparisons of the use of CdTe technology in relation to the other main types of solar panels in the current global market were made. It was verified that the telluride cadmium panels obtained the Performance Ratio of $84.86 \%$ which was the highest $P R$ in the analyzed panels and it was also shown to be the most ideal when the factor is to have the lowest loss of photovoltaic energy due to the temperature that was $-9 \%$ and the gain for the quality of the photovoltaic module was $+1.3 \%$. With this, the photovoltaic system of CdTe was the one that generated the most energy during the year, with a total of 1667 MWh and that consequently was the one that had the greater energy viability.
\end{abstract}

KEY-WORDS: Photovoltaic energy; Brazilian semi-arid; CdTe; 


\section{INTRODUÇÃO}

Com o mundo nas últimas décadas cada vez mais preocupado em relação as políticas ambientais e a procura de desenvolvimento de tecnologias na área de fontes de energia renováveis, a energia solar surge como alternativa para a diminuição da dependência dos combustíveis fosseis. Em especial a energia fotovoltaica, que com o passar dos anos vem se tornando cada vez mais viável sua implantação devido as constantes secas, crescimento das tarifas de energia, crise de energia no setor elétrico e os constantes avanços e aperfeiçoamentos nas tecnologias de painéis fotovoltaicos.

Os painéis fotovoltaicos de telureto de cádmio que são baseados na tecnologia de filme fino, vem se mostrando nos últimos anos uma grande alternativa aos painéis solares de silício cristalino, o mesmo foi a único da tecnologia de filme fino que ultrapassou o custo/eficiência dos tradicionais painéis de silício cristalino numa parte significativa do mercado mundial de painéis solares. E com a chegada da série 6 dos módulos de CdTe da empresa First Solar a eficiência de painéis solares comerciais com base na tecnologia de CdTe chegaram em $18 \%$.

Os custos de produção dos painéis de CdTe para produção em grande escala são atrativamente baixos e esta tecnologia tem ótimas chances de surgir como um sério competidor no mercado fotovoltaico para geração de potência elétrica conforme Rüther [1].

Ainda segundo Rüther [1], pelo motivo das células de CdTe terem relativamente baixa abundância e conterem toxicidade esses aspectos devem ser levados em consideração, principalmente se esta tecnologia atingir quantidades mais significativas de produção (da ordem de GWp).

Dentre as células de filmes finos a tecnologia de CdTe é uma das que apresentam maior progresso e desenvolvimento nos últimos anos. Este progresso mostrou-se tão promissor que foi instalada uma central de geração de energia elétrica de 1,4MWp feita somente de módulos de CdTe em Dimbach, Alemanha conforme Oliveira [2]. Hoje em dia já é possível encontrar grandes centrais solares de CdTe como o projeto de Agua Caliente que tem capacidade de $290 \mathrm{MW}$ e que se encontra no estado do Arizona nos EUA conforme First Solar [4].

As células fotovoltaicas de CdTe mais comuns consistem de uma simples estrutura de heterojunção p-n. Nestas células usasse comumente o CdS (Sulfeto de Cádmio) como semicondutor do tipo $\mathrm{n}$, o qual juntamente com o óxido transparente condutivo e o vidro atua como "janela"para a radiação incidente, e o CdTe é o semicondutor do tipo $\mathrm{p}$ nessa heterojunção.

A estrutura mais comum e mais difundida para a fabricação das células fotovoltaicas de telureto de cádmio de baixo custo e alta eficiência é oriunda de uma estrutura na qual as partes ativas da célula são depositadas sobre um substrato de vidro que tem como função dar resistência mecânica à célula, e o tipo de vidro mais indicado para o substrato da célula de CdTe éo borossilicato por não permitir a difusão de impurezas.

Segundo Nobre, (2017) O semiárido Brasileiro tem o maior potencial solar fotovoltaico do Brasil e um dos maiores potenciais solares em relação ao mundo, esse potencial com as tecnologias atuais de geração de energia fotovoltaica e a distribuição fundiária de pequenas e médias propriedades é possível que se gere energia fotovoltaica ligadas ao SIN (sistema interligado nacional) tornando o semiárido brasileiro um elemento gerador de energia na matriz elétrica Brasileira.

Em relação ao semiárido Brasileiro, o uso de painéis de CdTe vem se apresentando entre uma das melhores alternativas para a produção de energia elétrica, devido a vantagem de que o mesmo tem uma alta absorção da radiação por conta de ele ser um material de gap de energia direto com gap de energia de cerca de $1.45 \mathrm{eV}$, que é bastante compatível com o espectro solar e quase ideal para converter a luz solar em energia elétrica usando apenas uma junção. Com isso eles sofrem bem menos impacto da perda de desempenho do painel solar nesse ambiente em relação às células de silício cristalino.

\section{MATERIAL E MÉTODOS}

Para a análise da tecnologia fotovoltaica de CdTe numa central geradora de $1 \mathrm{MWp}$ no semiárido Brasileiro, foi escolhida a cidade de Petrolina $\left(-9.39^{\circ} \mathrm{S}\right.$ e $\left.-40.51^{\circ} \mathrm{W}\right)$ por possuir uma posição estratégica no semiárido e os dados de 
valores médios de irradiação solar utilizados na simulação foram retirados do Meteonorm 7.1. Cuja toda simulação do projeto da geração de energia elétrica fotovoltaica foi feita usando o software PvSystem sua versão 6.72.

Todas as simulações foram feitas buscando a maior eficiência, mantendo os mesmos parâmetros do local, orientando os painéis fotovoltaicos ao norte geográfico e fixando em $10^{\circ}$ a inclinação com o azimute $0^{\circ}$, também para uma comparação justa foram usados o mesmo número de inversores que no caso foram 2 de potência nominal de $500 \mathrm{kWac}$ cada para uma potência nominal total de $1 \mathrm{MWac}$, cujo modelo escolhido por caráter de otimização e adequação para análisefoi o PVS800-57-0500kW-A da fabricante $A B B$ com tensão de operação de 450 à $825 \mathrm{~V}$, que fazem a conversão da energia em corrente continua produzida pelos painéis para corrente alternada,alterando apenas o tipo e modelo de painel fotovoltaico que consequentemente dependendo da características de cada um, buscando sempre a melhor otimização e eficiência do projeto, mudou-se a quantidade de painéis usados, os arranjos, strings e etc.

Parao estudo foi escolhido como referência da tecnologia de telureto de cádmio o painel com a maior potência e consequentemente mais eficiente no mercado global atual, e o mesmo é da fabricante First Solar modelo FS-6445, de potência de pico de $445 \mathrm{Wp}$,e ele foi comparado consequentemente com os painéis com maiores potencias e eficiências atualmente das cinco maiores fabricantes de painel solar do mundo que segundo o Portal Solar [4], são a Jinko Solar, Trina Solar, Canadian Solar, JÁ Solar e por último a Hanwha Q-CELLS, curiosamente os painéis solares com maior potência e eficiência de ambas fabricantes são de silício monocristalino.

$\mathrm{Na}$ Tabela 1 é citado e comparado os painéis utilizados nesse estudo, como podemos destacar o modelo e a fabricante de cada painel, e suas respectivas potências pico e a quantidade total de painéis utilizadas nessa pesquisa.
Tabela 1: Comparação dos módulos com suas respectivas potências picos e número total de painéis.

\begin{tabular}{|c|c|c|c|}
\hline Fabricante & Modelo & Potência-Pico & № Total de Painéis \\
\hline First Solar & FS-6445 & $445 W p$ & 2247 \\
\hline JinkoSolar & JKM 370M-72 & $370 W p$ & 2703 \\
\hline Trina Solar & TSM-345DD14A & $345 W p$ & 2898 \\
\hline Canadian Solar & CS3U-380MS & $380 W p$ & 2635 \\
\hline JA Solar & JAP6-72-330/3BB & $330 W p$ & 3026 \\
\hline Hanwha Q-CELLS & Q.PEAK L-G4.2370 & 370Wp & 2703 \\
\hline
\end{tabular}

Fonte: Autor (2018).

\section{RESULTADOS E DISCUSSÃO}

Por meio da Figura 1 observa-se o diagrama de perdas durante 0 ano todo do sistema fotovoltaico com painéis de CdTe da Fisrt Solar, destacando-se como resultado final o valor de 1667 MWh que é a energia injetada na rede depois de todas as perdas, onde podemos também obter e destacar os percentuais das perdas de energia fotovoltaica devido a irradiância que foi de $-2.3 \%$, as perdas de energia fotovoltaica decorrente a temperatura que foi de $9 \%$ e o ganho pela qualidade do modulo fotovoltaico que foi de $+1.3 \%$.

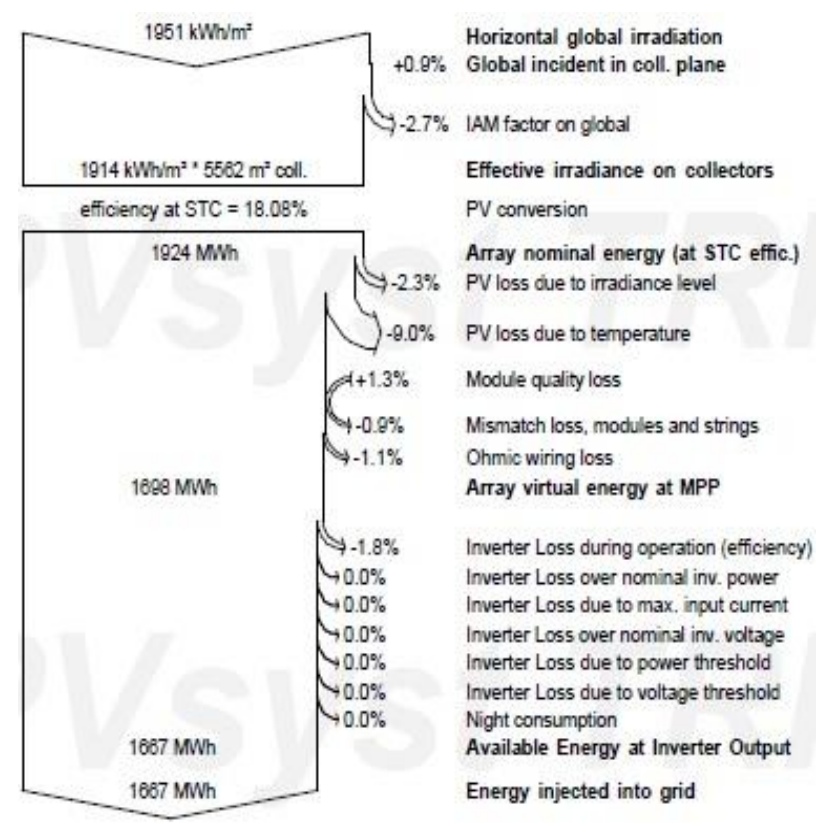

Figura 1: Diagrama de Perdas do Painel de CdTe da First Solar durante o ano.

Fonte: Autor (2018).

Na Figura 2 tem-se o diagrama de perdas dopainel de silício da Canadian Solar, onde vamos poder concluir posteriormente que dentre os sistemas usando os painéis da tecnologia de silício 
cristalino o que mais injetou energia na rede durante 0 ano foi $o$ da fabricante Canadian Solarque teve o valor de 1664 MWhe o mesmo também foi o que teve a menor perda de energia fotovoltaica decorrente a temperatura que foi de $9.7 \%$, já a perda de energia fotovoltaica devido a irradiância foi de $-0.4 \%$, e o ganho pela qualidade do modulo fotovoltaico foi de $+0.3 \%$.

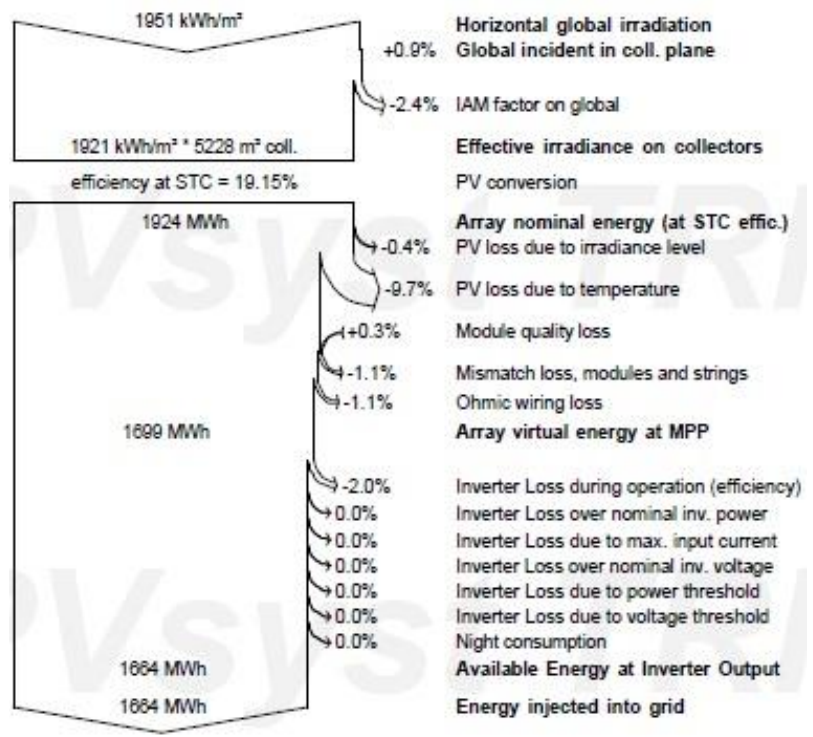

Figura 2: Diagrama de Perdas do Painel de Silício da Canadian Solar durante o ano.

Fonte: Autor (2018).

Já nas Figuras 3, 4, 5 e 6temos respectivamente os diagramas de perdas dos sistemas com os painéis de silício da JA Solar, Jinko Solar, Trina Solar e Hanwha Q CELLS, onde podemos observar que o sistema onde menos se injetou energia fotovoltaica na rede foi o da JA solar com o valor de 1629 MWh.

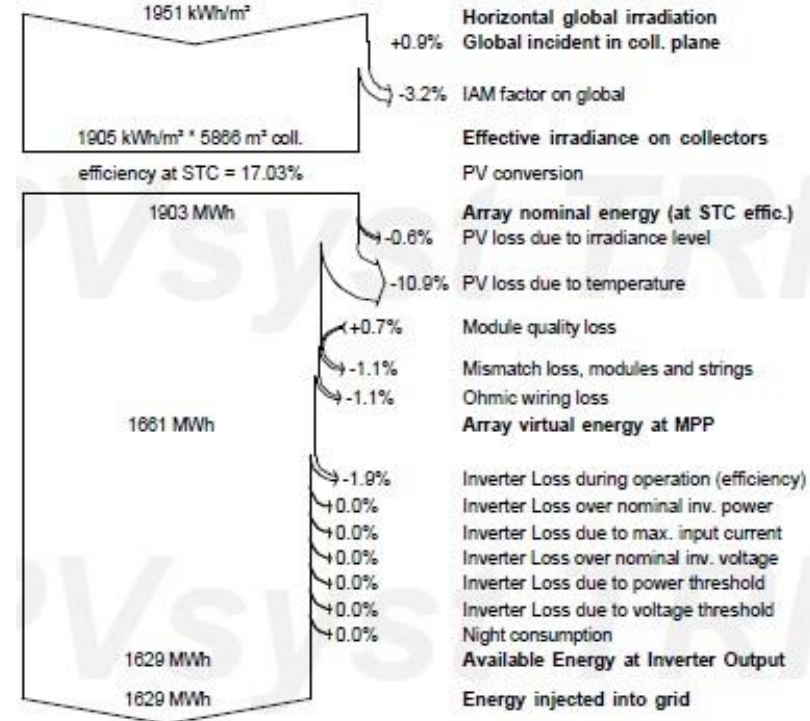

Figura 3: Diagrama de Perdas do Painel de Silício da JA Solar durante o ano.

Fonte: Autor (2018).

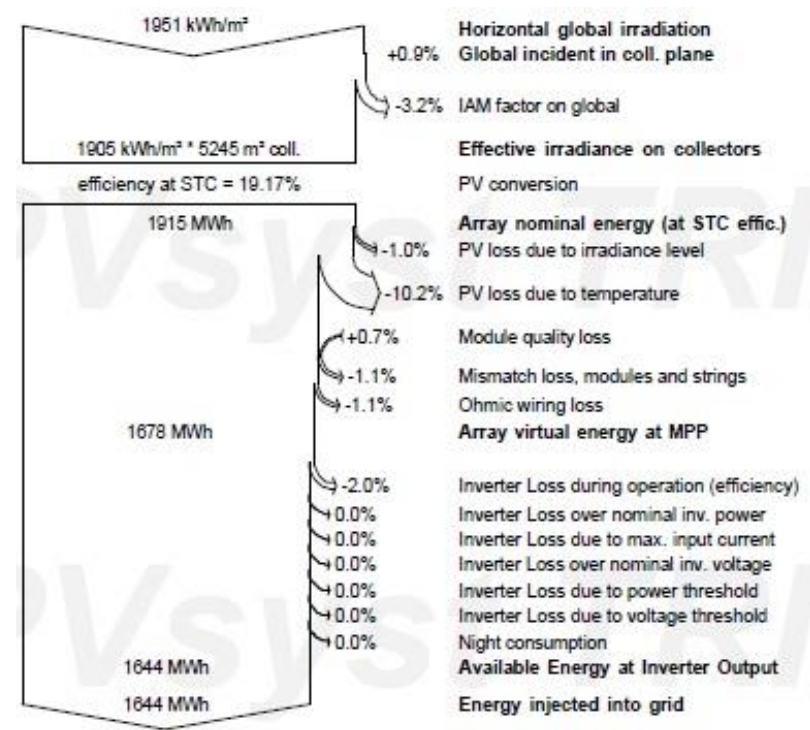

Figura 4: Diagrama de Perdas do Painel de Silício da Jinko Solar durante o ano.

Fonte: Autor (2018). 


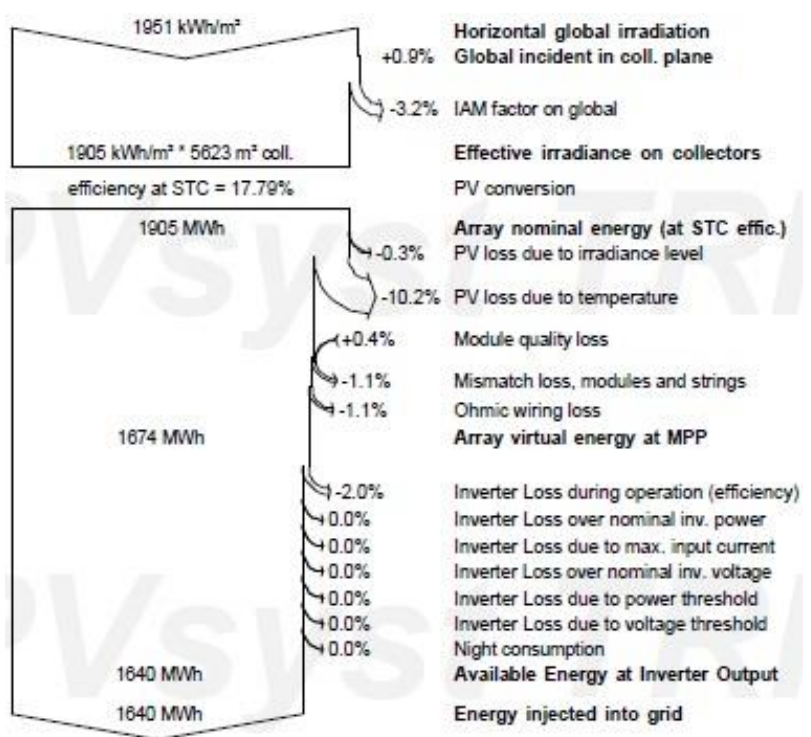

Figura 5: Diagrama de Perdas do Painel de Silício da Trina Solar durante o ano.

Fonte: Autor (2018).

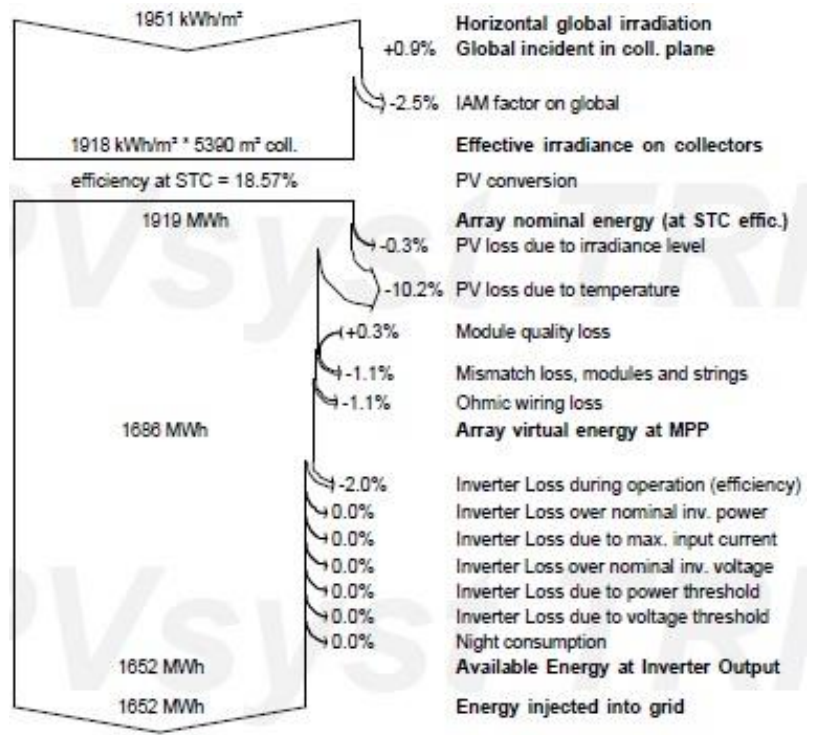

Figura 6: Diagrama de Perdas do Painel de Silício da Hanwha $Q$ Cells durante o ano.

Fonte: Autor (2018).

Uma grande característica quando se quer comparar diferentes sistemas fotovoltaicos é verificar o Performance Ratio (PR) de cada sistema. Que objetivamente a performance ratio determina a relação entre a possível geração de energia teórica e energia real. Esta é largamente independente da radiação num sistema fotovoltaico e do posicionamento de um sistema fotovoltaico.

A seguir na Figura 7 podemos observar o Performance Ratio (PR) de cada sistema fotovoltaico simulado, com isso nota-se que 0 sistema no qual utilizou os painéis de CdTe foi o que teve o maior Performance Ratio, PR de $84,66 \%$, indicando que o sistema onde se usa 0 painel de telureto de cádmio é o mais eficiente dentre os analisados.

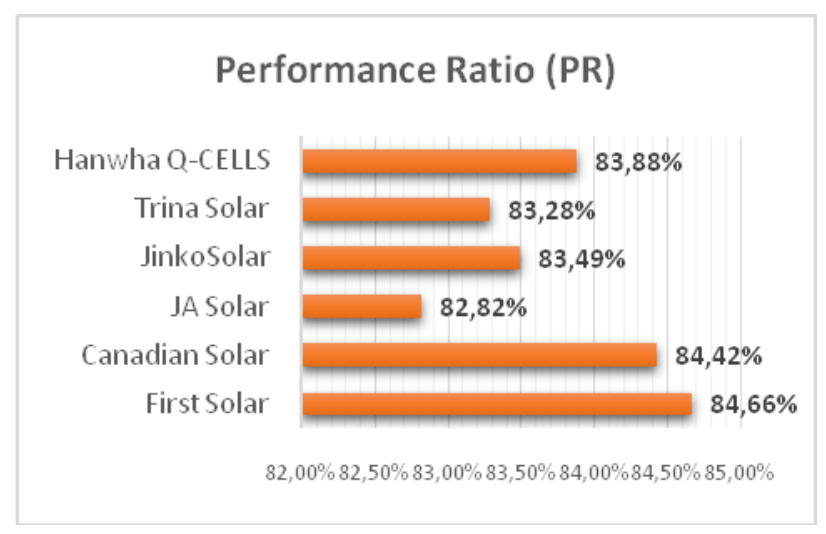

Figura 7: Comparação do Performance Ratio (PR) dos sistemas fotovoltaicos simulados. Fonte: Autor (2018).

\section{CONCLUSÕES}

Feita a análise e comparação da geração de energia no semiárido brasileiro usando painéis de CdTe em relação aos seus principais concorrentes no mercado global atual foi observado que o sistema no qual utilizou a tecnologia de CdTe teve a maior produção de energia na qual foi injetada na rede, devido ao fato de que os painéis de telureto de cádmio tiveram a menor perda de energia fotovoltaica decorrente a temperatura e também foi o que teve o maior ganho pela qualidade do modulo fotovoltaico, tais características queinfluenciaram diretamente também no resultado no qual the deu o maior Performance Ratiodentre os painéis analisados e mostrou consequentemente a sua maior viabilidade energética em relação as outras tecnologias.

\section{REFERÊNCIAS}

[1] RÜTHER, R. Edifícios Solares

Fotovoltaicos. Florianópolis: LABSOLAR, 2004.

[2] OLIVEIRA, H. E. Tecnologia Fotovoltaica em Filmes Finos (Películas Delgadas). Universidade Federal de Lavras, Brasil, 2008.

[3] NOBRE, P. Entrevista concedida ao IPEA, Brasília, 2017. Disponível em: 
https://www.youtube.com/watch?v=4bZd7h xllOc. Acessado em: 14 nov. 2017.

[4] FIRSTSOLAR. Disponível em: http://www.firstsolar.com/AboutUs/Overview Acessado em: 15 nov. 2017

[5] PORTAL SOLAR. Disponível em: https://www.portalsolar.com.br/blogsolar/painel-solar/os-10-maiores-fabricantesde-painel-solar-em-2017.html. Acessado em: 10 maio de 2018. 